
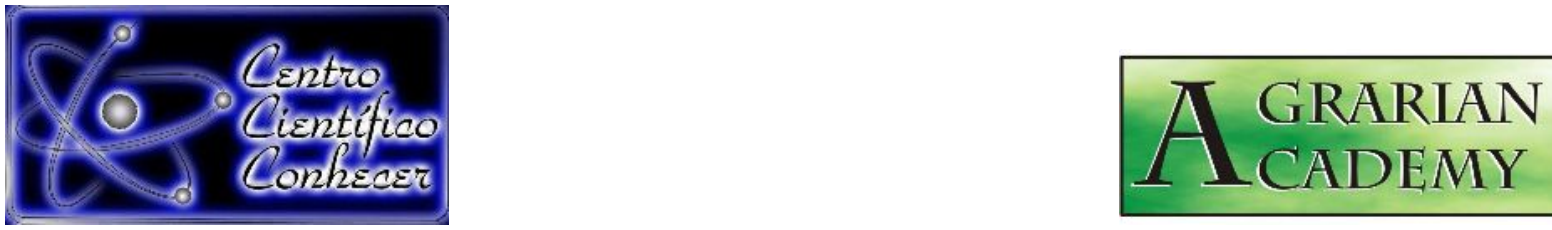

\title{
ANÁLISE PRELIMINAR DOS PARÂMETROS FÍSICO-QUÍMICOS E MICROBIOLÓGICOS DAS ÁGUAS DO CÓRREGO PARAÍSO - TRECHO URBANO DO DISTRITO DE VIEIRA MACHADO, EM MUNIZ FREIRE-ES
}

\author{
Caio Henrique Ungarato Fiorese ${ }^{1}$, Donizete Andrade ${ }^{2}$, Eduardo de Moraes \\ Agrizzi $^{3}$, Herbert Torres ${ }^{4}$. \\ ${ }^{1}$ Graduando em Engenharia Ambiental no Centro Universitário São Camilo, \\ Cachoeiro de Itapemirim, Espírito Santo, Brasil. (caiofiorese@hotmail.com). \\ 2,3 Graduandos em Engenharia Ambiental no Centro Universitário São Camilo, \\ Cachoeiro de Itapemirim, Espírito Santo, Brasil. \\ ${ }^{4}$ Professor Assistente do Centro Universitário São Camilo, Cachoeiro de Itapemirim, \\ Espírito Santo, Brasil.
}

Recebido em: 02/06/2019 - Aprovado em: 15/06/2019 - Publicado em: 22/07/2019 DOI: 10.18677/Agrarian_Academy_2019a3

\begin{abstract}
RESUMO
Estudos que abordam análises de qualidade de recursos hídricos são de extrema importância, para subsidiar ações de saneamento ambiental e melhoria da qualidade de vida. Considerando tal relevância, o objetivo deste estudo foi avaliar preliminarmente a qualidade da água do Córrego Paraíso, no trecho urbano do distrito de Vieira Machado, zona rural de Muniz Freire/ES. Este trabalho faz parte de um projeto que visa à melhoria do saneamento ambiental na região considerada. Foram definidos três pontos de análises em relação à área urbana (a montante; na área urbana; a jusante), onde foram feitas as análises físico-químicas e a coleta de água. As amostras foram encaminhadas a um laboratório para a execução das análises microbiológicas através da técnica de tubos múltiplos, que se dividiu em: teste presuntivo e teste confirmativo, nas concentrações 1:1, 1:10 e 1:100, para determinar a presença de coliformes fecais e Escherichia coli e, posteriormente, enquadrar os resultados conforme a legislação. Com exceção do pH, que apresentou caráter mais ácido, todos os parâmetros estiveram em conformidade com a legislação. Todavia, a turbidez e as concentrações e os déficits de oxigênio dissolvido foram piorando em direção à jusante, aliados ao aumento da temperatura, evidenciando a influência do distrito na qualidade da água. Foi detectada elevada presença de coliformes, em decorrência, principalmente, da ausência de sistema de tratamento de efluentes domésticos. A aplicabilidade do projeto juntamente com ações de saneamento ambiental e mitigação dos impactos ambientais serão de suma importância para melhorar a qualidade hídrica do Córrego Paraíso.
\end{abstract}

PALAVRAS-CHAVE: Análise de Água; Efluentes Domésticos; Saneamento Ambiental. 


\title{
PRELIMINARY ANALYSIS OF THE PHYSICAL-CHEMICAL AND MICROBIOLOGICAL PARAMETERS OF THE WATER OF THE PARAÍSO STREAM - URBAN AREA OF THE DISTRICT OF VIEIRA MACHADO, IN MUNIZ FREIRE-ES
}

\begin{abstract}
Studies that address the analysis of the quality of water resources are of extreme importance to subsidize actions of environmental sanitation and to improve the quality of life. Considering this relevance, the objective of this study was to preliminarily evaluate the water quality of the Paraíso stream, in the Vieira Machado urban stretch, in the rural area of Muniz Freire/ES. This work is part of a project to improve environmental sanitation in the region. Three points of analysis were defined in relation to the urban area (upstream; in the urban area; downstream), where physical-chemical analyzes and water collection were performed. The samples were sent to a laboratory for the microbiological analysis through the multiple tube technique, which was divided into: presumptive test and confirmatory test, in concentrations 1: 1, 1:10 and 1: 100, to determine the presence of fecal coliforms and Escherichia coli, and then frame the results according to the legislation. With the exception of $\mathrm{pH}$, which was more acidic, all parameters were in accordance with legislation. However, turbidity and dissolved oxygen concentrations and deficits were worsening downstream, coupled with rising temperature, evidencing the district's influence on water quality. A high presence of coliforms was detected, mainly due to the absence of a domestic effluent treatment system. The applicability of the project together with actions of environmental sanitation and mitigation of environmental impacts will be of paramount importance to improve the water quality of the Paraíso stream.
\end{abstract}

KEYWORDS: Water Analysis; Domestic Effluents; Environmental Sanitation.

\section{INTRODUÇÃO}

A água é um elemento de imensa importância na vida humana, pois, além da sobrevivência, é um elemento crucial para o desenvolvimento de diversas atividades como, por exemplo, geração de energia, diluição de efluentes domésticos e industriais, captação de água para potabilização e manutenção do equilíbrio ecológico e ambiental (GARCIA et al., 2015).

A disponibilidade de água potável, segura e saudável para todos, tem sido um dos desafios mais significativos na regulamentação governamental e da investigação científica, pois a potabilidade da água é pré-requisito para a saúde de qualidade e formas de subsistência (MELLO; RESENDE, 2015).

Grande parte da população residente nas zonas rurais possui sistema próprio de abastecimento de água (através de poços artesianos, por exemplo), ou é integrante da sociedade hídrica em uma comunidade, usufruindo da água oriunda de rios, córregos, nascentes, etc (BISOGNIN et al., 2017). Todavia, as atividades humanas têm gerado grandes impactos nos sistemas aquáticos de variadas formas, sendo que os despejos domésticos causam profundas alterações, em qualidade e quantidade, nesses ambientes, devido à inserção de grandes quantidades de substâncias estranhas (STROHSCHOEN et al., 2009).

A grande quantidade de rios poluídos e a dificuldade de abastecimento vivenciada por várias localidades, sem contar a associação desse problema com a 
saúde pública, têm ligado o alerta em muitos gestores públicos (ZSCHORNACK; OLIVEIRA, 2017). Por isso, na atualidade, a preocupação mundial está voltada à qualidade da água para consumo humano, uma vez que o desenvolvimento das cidades e o crescimento populacional influenciaram diretamente no aumento da poluição e degradação dos recursos naturais (GLÓRIA et al., 2017).

A presença de contaminantes em um corpo hídrico é avaliada conforme suas características, sendo composta em três grupos de análises: características físicas, químicas e biológicas. As características físicas referem-se à presença de sólidos na água, ao passo que as características biológicas tratam-se dos organismos presentes e as características químicas referem-se às substâncias dissolvidas na água amostrada (NEVES et al., 2015).

$\mathrm{Na}$ zona rural, algumas das fontes de contaminação hídrica são: o uso indiscriminado de agrotóxicos, lançamento de esgoto doméstico in natura, manejo inadequado da agropecuária e destinação inadequada de resíduos sólidos. De modo geral, essas áreas não possuem um sistema de tratamento individual ou coletivo para consumo da água, o que pode acarretar a ocorrência de doenças indesejáveis (LEITE et al., 2015).

Portanto, é relevante a realização de levantamentos e diagnósticos dos problemas que possam acarretar no aporte desses poluentes aos cursos hídricos (ALVES et al., 2017). A avaliação da qualidade da água para consumo humano é importante, pois a mesma tem capacidade de veicular expressivas quantidades de contaminantes associados a vários problemas de saúde (ANDRADE et al., 2017). Nesse contexto, o objetivo deste trabalho foi fazer uma análise da qualidade da água do Córrego Paraíso, na área urbana do distrito de Vieira Machado em Muniz Freire (ES) como forma de subsidiar ações de melhorias na área.

\section{MATERIAL E MÉTODOS}

A pesquisa considerou como local de estudo o Córrego Paraíso, no trecho urbano do distrito de Vieira Machado, situado na zona rural do município de Muniz Freire, mesorregião Sul do estado do Espírito Santo. Este recurso hídrico é utilizado para abastecer o distrito local, além de localidades do entorno. No distrito, por não haver um sistema de tratamento coletivo, o principal sistema adotado é o de fossas individuais que, no entanto, não foram aderidas por todos os moradores locais, tendo, portanto, a ocorrência do lançamento de esgoto in natura no Córrego Paraíso. A Figura 1 mostra, em detalhes, a localização do distrito de Vieira Machado. 


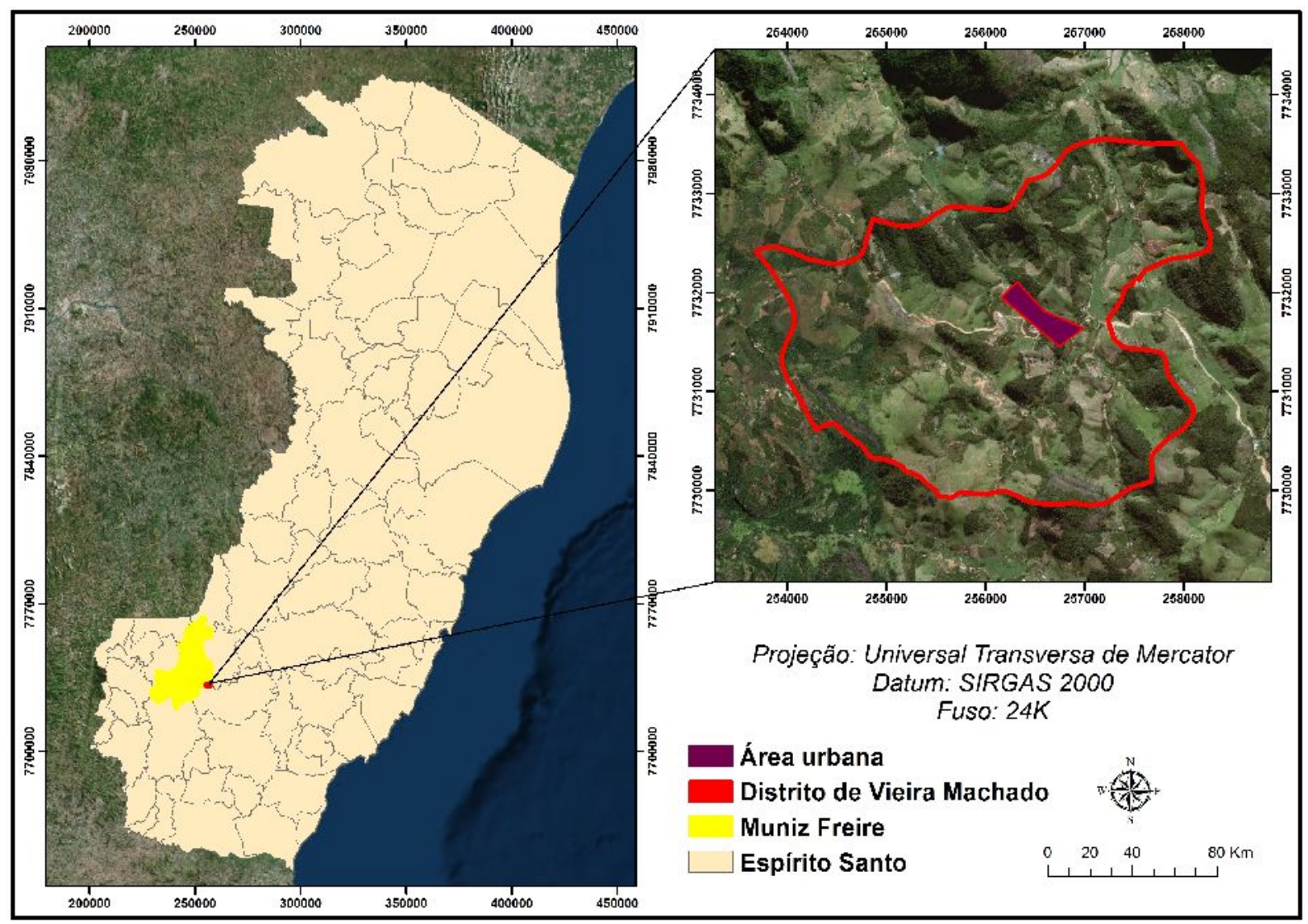

FIGURA 1. Localização do distrito de Vieira Machado.

Fonte: Geobases; Instituto Jones dos Santos Neves (IJSN) (2019).

Editado pelos Autores (2019).

Este trabalho faz parte do projeto "Águas Limpas de Vieira Machado-ES", proposto pelos autores desta pesquisa, que visa propor melhorias da qualidade hídrica e ambiental do Córrego Paraíso e de sua microbacia, além do saneamento local por meio da implantação de sistema de tratamento do efluente doméstico da região. A princípio, utilizando o programa computacional ArcGis® na versão 10.2, foram delimitados três pontos de coleta e análise da água do córrego, sendo: um ponto à montante do distrito; um ponto na área urbana e; um ponto à jusante do distrito. Respectivamente, denominados de pontos 1, 2 e 3 . Os pontos foram delimitados considerando a acessibilidade e com maior equidistância possível entre si. Cada ponto, inicialmente, foi percorrido para registrar, com auxílio de imagens fotográficas, a situação de cada um. A Figura 2 mostra a representação, em mapa temático, dos pontos amostrados e as respectivas coordenadas geográficas. 


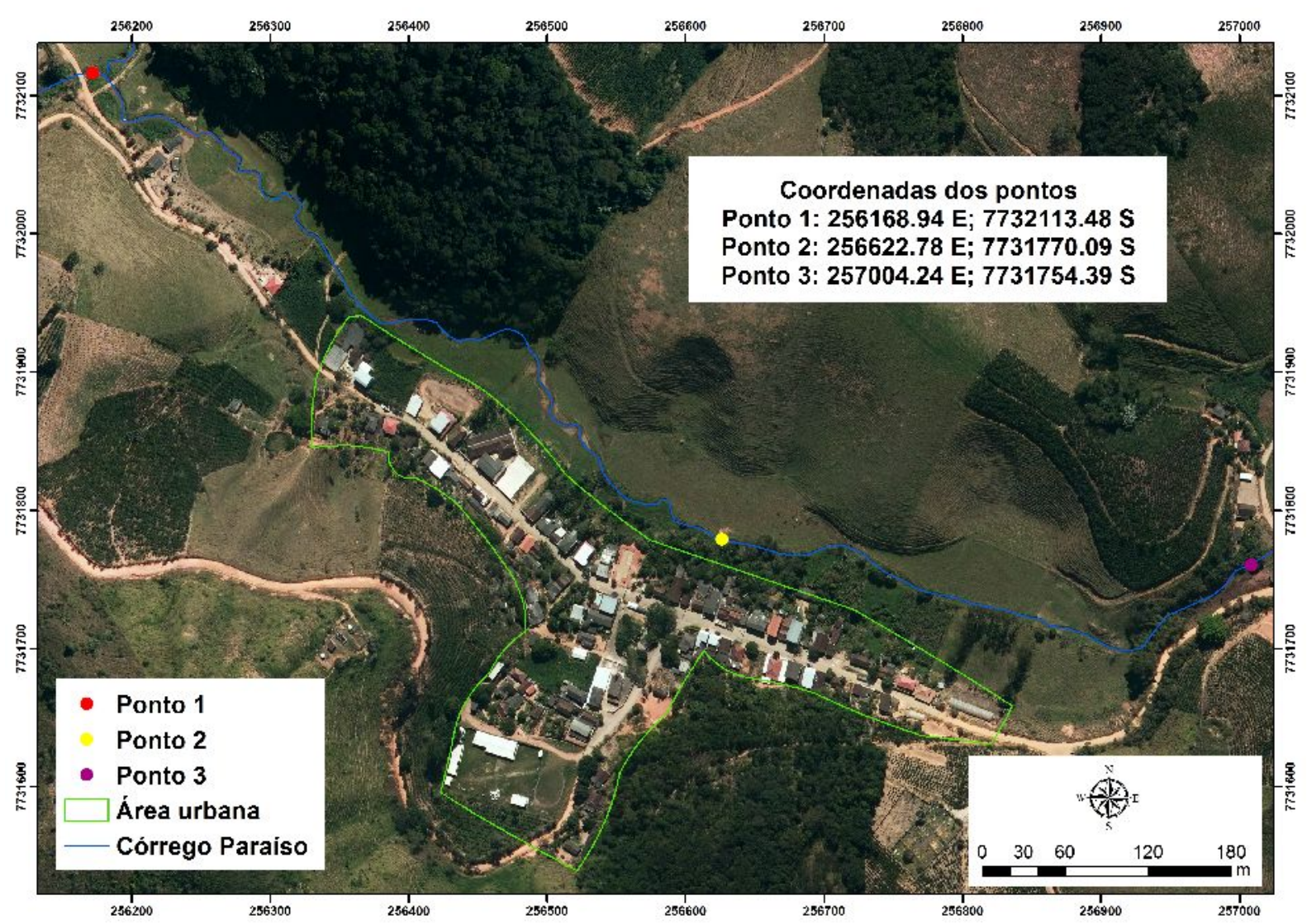

FIGURA 2. Distribuição e coordenadas dos pontos amostrados. Fonte: Os Autores (2019).

Toda a coleta e análise foram baseadas no Manual Prático de Análise de Água (BRASIL, 2013). Inicialmente, com auxílio de frascos de vidro devidamente identificados para cada local amostrado, foram coletadas as amostras de água in loco. Em cada ponto, foram medidos os seguintes parâmetros: concentração de oxigênio dissolvido, temperatura e sais solúveis com auxílio de um oxímetro medidor de multiparâmetros e; $\mathrm{pH}$ com auxílio de fitas de $\mathrm{pH}$. Por meio de prancheta de campo, os resultados coletados na pesquisa de campo foram devidamente registrados.

Os frascos de vidro, após a coleta das amostras, foram devidamente armazenados em isopor, com intuito de evitar o contato com o meio externo durante o transporte e, com isso, interferir nos resultados a serem determinados posteriormente. As amostras foram encaminhadas a um laboratório devidamente credenciado, onde foram feitas, inicialmente, as análises de turbidez e condutividade elétrica, por meio de turbidímetro e condutivímetro, respectivamente. Os resultados foram devidamente anotados para cada ponto.

Em seguida, foram feitas as análises microbiológicas das amostras, que foram dividas em: teste presuntivo e teste confirmativo. No presuntivo, em tubos de ensaio e com tubos de Durham, foram utilizados os meios de cultura caldo Lactosado Simples, com concentração de 1:1 da amostra e; caldo Lactosado Duplo, com concentrações de 1:10 e 1:100 da amostra. Para cada concentração, foram utilizados cinco tubos de ensaio, totalizando 15 tubos de ensaio por amostra e 45 tubos de ensaio utilizados em todos os pontos. Após a diluição, os meios de cultura com as alíquotas das amostras foram incubados em estufa a $35^{\circ} \mathrm{C}$ de temperatura por cerca de 24 horas. A formação de gases nos tubos de Durham indicou resultado AGRARIAN ACADEMY, Centro Científico Conhecer - Goiânia, v.6, n.11; p.26 2019 
positivo, ou seja, houve presença de bactérias do grupo coliforme, ao passo que a ausência de gás indicou resultado positivo, ou seja, não foram detectadas bactérias do grupo coliforme nos tubos.

No teste confirmativo, foram utilizados os tubos positivos do teste anterior, utilizando os meios de cultura EC e Verde Brilhante (VB). Com auxílio de uma alça de platina, foi transferida uma porção da solução dos tubos positivos para os tubos com os meios EC e VB. Após a finalização desse procedimento para todos os tubos positivos, os meios de cultura com as alíquotas foram incubados em estufa a $44,5^{\circ} \mathrm{C}$ de temperatura por um período de 24 horas, sendo que a formação de gás nos tubos de Durham indicou resultado positivo, ou seja, houve presença de coliformes termotolerantes ou de Escherichia coli, ao passo que a ausência de gás indicou que não houve detecção das bactérias supracitadas.

Os resultados das análises microbiológicas foram devidamente registrados para cada ponto amostrado, bem como, para cada combinação de tubos, foi estimado o número mais provável (NMP) de bactérias para cada $100 \mathrm{~mL}$ da amostra. Os dados obtidos foram enquadrados conforme a resolução CONAMA n 357 (BRASIL, 2005), para, também, realizar a classificação do corpo hídrico estudado e posterior estudo dos resultados. De acordo com Fagundes et al. (2016), a classe de um curso hídrico abrange os critérios ou as condições das águas quanto aos usos a que se destina e os requisitos a serem observados.

Foi estimado também o déficit de oxigênio dissolvido para cada ponto amostrado. Esse déficit, segundo Jordão e Pessoa (2014), é a diferença entre a concentração de saturação de oxigênio dissolvido e a concentração de oxigênio dissolvido num dado ponto, ou seja (equação 1):

$$
D=C s-C
$$

Sendo:

Cs = concentração de saturação de oxigênio dissolvido (mg/L);

$\mathrm{C}$ = concentração de oxigênio dissolvido determinada pelo oxímetro (mg/L);

$\mathrm{D}=$ déficit de oxigênio dissolvido ( $\mathrm{mg} / \mathrm{L})$.

O valor de Cs é tabelado e determinado a partir da temperatura, em graus Celsius, determinada pelo oxímetro no ponto amostrado. Valores negativos para o déficit de oxigênio indicam excedente de oxigênio, ao passo que valores negativos influem perda desse gás num dado ponto do curso hídrico (JORDÃO; PESSOA, 2014). Após as estimativas, os resultados do déficit de oxigênio dissolvido foram analisados conforme a literatura considerada, assim como os demais parâmetros determinados neste estudo.

\section{RESULTADOS E DISCUSSÃO}

De acordo com a resolução CONAMA $n^{\circ} 357$ e com as formas de utilização do recurso hídrico, as águas do Córrego Paraíso são classificadas como classe 1 , ou seja, águas destinadas ao abastecimento para consumo humano após tratamento simplificado, à proteção das comunidades aquáticas, à recreação de contato primário, à aquicultura e pesca e à irrigação de hortaliças e frutas. $O$ enquadramento do Córrego Paraíso nesta classe ocorreu devido ao fato de a maioria dos valores dos parâmetros considerados se encaixarem com as características determinadas pela resolução na classificação citada. A Tabela 1 
mostra os resultados obtidos com as análises físico-químicas para os pontos amostrados.

TABELA 1. Resultados das análises físico-químicas.

\begin{tabular}{cccc}
\hline Parâmetro & Ponto 1 & Ponto 2 & Ponto 3 \\
\hline Temperatura & $21,1^{\circ} \mathrm{C}$ & $21,8^{\circ} \mathrm{C}$ & $22,4^{\circ} \mathrm{C}$ \\
\hline $\mathrm{pH}$ & 5,0 & 5,0 & 5,5 \\
\hline Sais solúveis & $7,96 \mathrm{mg} \mathrm{L}^{-1}$ & $7,68 \mathrm{mg} \mathrm{L}^{-1}$ & $7,14 \mathrm{mg} \mathrm{L}^{-1}$ \\
\hline Oxigênio dissolvido & $93,5 \%$ & $91,6 \%$ & $86,1 \%$ \\
\hline Turbidez & $11,6 \mathrm{NTU}$ & $16,6 \mathrm{NTU}$ & $20,9 \mathrm{NTU}$ \\
\hline Condutividade elétrica & $0,04 \mathrm{mS} \mathrm{cm}^{-1}$ & $0,04 \mathrm{mS} \mathrm{cm}^{-1}$ & $0,04 \mathrm{mS} \mathrm{cm}^{-1}$ \\
\hline
\end{tabular}

Ao longo do trecho analisado, mesmo tendo apresentado valores entre $21^{\circ} \mathrm{C}$ e $22,5^{\circ} \mathrm{C}$, houve aumento da temperatura da água, variando em $0,7^{\circ} \mathrm{C}$ para o ponto 2 e em $0,4^{\circ} \mathrm{C}$ do ponto 2 para o ponto 3 . A resolução CONAMA n ${ }^{\circ} 357 / 2005$ não aborda a questão da temperatura, mas é um parâmetro importantíssimo, discutido a partir da literatura considerada.

$\mathrm{O}$ aquecimento das águas superficiais de rios pode ter origem em processos naturais, como os geotérmicos, sazonalidade da temperatura ambiente e da insolação, e da redução da vazão. Também pode ser oriunda de processos antrópicos diretos, como a descarga de efluentes com temperatura diferente do corpo receptor e pelo calor liberado na oxidação do poluente lançado, ou processos indiretos, através do represamento de água e desmatamento das áreas de drenagem (PERCEBON et al., 2005).

Portanto, para as águas do segmento analisado do Córrego Paraíso, além de trechos desprovidos de vegetação ciliar nos pontos analisados, também há impactos quanto ao lançamento de efluentes domésticos, embora não sejam em grandes quantidades devido ao fato do distrito de Vieira Machado estar em área rural. Além disso, a presença de atividades agropecuárias próximas a este curso hídrico é outro fator impactante no aumento da temperatura. Em termos ambientais, a queda dos valores da temperatura ao longo do percurso do córrego pode ser danosa à biota aquática, provocando até mesmo 0 desaparecimento de espécies $e$, consequentemente, prejudicando a qualidade da água.

Os valores do $\mathrm{pH}$ estiveram de 5,0 a 5,5. Todavia, ficaram abaixo do mínimo permitido pela resolução $n^{\circ} 357 / 2005$ do CONAMA, que aborda valores de $\mathrm{pH}$ de 6,0 a 9,0 para um corpo hídrico de classe 1. Segundo a Companhia Ambiental do Estado de São Paulo (CETESB, 2019), valores de $\mathrm{pH}$ acima de 7,0 indicam maior grau de alcanilidade da água, ao passo que valores abaixo de 7,0 indicam maior teor de acidez.

Ainda de acordo com a CETESB, valores baixos para o $\mathrm{pH}$, conforme visto neste trabalho em comparação com a resolução $n^{\circ} 357$ do CONAMA, são danosos aos peixes e à biota aquática. Todavia, $\mathrm{o} \mathrm{pH}$ também pode variar conforme as características do solo e também de seu uso, uma vez que a utilização excessiva de fertilizantes químicos e agrotóxicos podem desencadear problemas quanto ao $\mathrm{pH}$ da água. Hipótese esta que pode ser considerada, devido à predominância da agropecuária na região abastecida pelo Córrego Paraíso.

Os valores de oxigênio dissolvido visualizados estiveram em conformidade com o valor mínimo estabelecido pela legislação. Todavia, tiveram decréscimo ao longo do trecho analisado, o que é um fator preocupante quanto à qualidade deste corpo hídrico. O oxigênio dissolvido é um parâmetro de grande importância a ser 
analisado, ao levar em consideração o desenvolvimento de espécies aquáticas e o consumo humano, sendo que, quando há variações de teores fora do limite estabelecido, pode indicar má qualidade hídrica (BATISTA et al., 2017). A queda nos valores desse parâmetro pode ocorrer através do volume de matéria orgânica lançado em um curso hídrico, devido à maior proliferação de bactérias e, consequentemente, maior atividade de respiração das mesmas (SILVA; OLIVEIRA, 2014) ou por meio da ausência de quedas d'água (cachoeiras ou corredeiras) ao longo do percurso do rio.

No Córrego Paraíso, a ausência de quedas d'água ao longo do trecho analisado juntamente com o lançamento de dejetos residenciais são os fatores mais prováveis para o decréscimo de oxigênio dissolvido visualizado, apesar dos valores serem satisfatórios conforme a norma vigente. Para o ecossistema aquático, mesmo com tais valores satisfatórios, a queda desse parâmetro influi na deterioração das condições saudáveis de vida e, com isso, na piora da qualidade hídrica.

Os valores de sais solúveis variaram de $7,96 \mathrm{mg} \mathrm{L}^{-1}$ a $7,14 \mathrm{mg} \mathrm{L}^{-1}$ no trecho estudado, mas tiveram um decréscimo. Andrade et al. (2017), em estudos acerca da qualidade da água do rio Castelo, também visualizaram redução da concentração de sais na direção jusante. Esses sais, de acordo com Renovato et al. (2013), favorecem o crescimento das plantas, mas, em grandes concentrações, tornam-se prejudiciais, além de afetar o sabor da água e, consequentemente, influenciar no consumo humano. Portanto, para as águas do Córrego Paraíso, as concentrações de sais estiveram em níveis aceitáveis.

A turbidez, apesar de ter apresentado crescimento do ponto 1 ao ponto 3 , esteve em conformidade com a legislação, ou seja, não excedeu os limites estabelecidos. Elevados teores de turbidez na água a tornam inviável para o consumo humano e animal e para seu uso na irrigação e balneabilidade, além de desencadear vários problemas ao funcionamento do ecossistema natural (ROBERTO et al., 2017). Por isso, no recurso hídrico estudado, o parâmetro turbidez permite boas condições de vida aquática e, aliada a essa vantagem, permite o uso das águas para irrigação e consumo humano após seu tratamento.

Em todos os pontos, a condutividade elétrica das águas do Córrego Paraíso apresentou o mesmo valor $\left(0,04 \mathrm{mS} \mathrm{cm}^{-1}\right)$. Esse parâmetro, segundo Santos e Mohr (2013), significa a capacidade de transmitir corrente elétrica e, apesar de não representar riscos à saúde humana, serve como base para estimar outros parâmetros, como a concentração de sólidos totais dissolvidos que, quando em excesso, pode ser prejudicial ao paladar e a saúde humana. A Tabela 2 mostra o resultado dos parâmetros microbiológicos referentes ao teste presuntivo.

TABELA 2. Resultados do teste presuntivo; NMP = número mais provável.

\begin{tabular}{cccc}
\hline Parâmetro & Ponto 1 & Ponto 2 & Ponto 3 \\
\hline Lactosado Duplo $(1: 1)$ & $5+$ & $5+$ & $5+$ \\
\hline Lactosado Simples $(1: 10)$ & $5+$ & $5+$ & $5+$ \\
\hline Lactosado Simples $(1: 100)$ & $5+$ & $5+$ & $5+$ \\
\hline NMP $(100 \mathrm{~mL})$ & $\geq 1600$ & $\geq 1600$ & $\geq 1600$ \\
\hline
\end{tabular}

Portanto, todos os tubos foram positivos, ou seja, foi determinada a presença de bactérias do grupo coliforme, necessitando, assim, da realização do teste confirmativo para coliformes termotolerantes e Escherichia coli. Dessa forma, nenhum dos tubos apresentou ausência desses coliformes e, portanto, nenhum foi 
descartado. As Tabelas 3 e 4 mostram, respectivamente, os resultados do teste confirmativo para coliformes termotolerantes e Escherichia coli.

TABELA 3. Resultados do teste confirmativo quanto à inoculação ao meio de cultura Verde Brilhante (VB); NMP = número mais provável.

\begin{tabular}{cccc}
\hline Parâmetro & Ponto 1 & Ponto 2 & Ponto 3 \\
\hline VB (1:1) & $5+$ & $5+$ & $5+$ \\
\hline VB $(1: 10)$ & $5+$ & $5+$ & $5+$ \\
\hline VB $(1: 100)$ & $5+$ & $5+$ & $5+$ \\
\hline NMP $(100 \mathrm{~mL})$ & $\geq 1600$ & $\geq 1600$ & $\geq 1600$ \\
\hline
\end{tabular}

TABELA 4. Resultados do teste confirmativo quanto à inoculação ao meio de cultura Escherichia coli (EC); NMP = número mais provável.

\begin{tabular}{cccc}
\hline Parâmetro & Ponto 1 & Ponto 2 & Ponto 3 \\
\hline EC (1:1) & $5+$ & $5+$ & $5+$ \\
\hline EC $(1: 10)$ & $3+$ & $3+$ & $3+$ \\
\hline EC $(1: 100)$ & $2+$ & $2+$ & $3+$ \\
\hline NMP/100 mL & 140 & 140 & 170 \\
\hline
\end{tabular}

Portanto, há presença de coliformes termotolerantes e bactérias do grupo Escherichia coli, por ter apresentado tubos positivos para ambos os testes. De acordo com a Portaria $n^{\circ} 2.914$ do Ministério da Saúde (BRASIL, 2011), um recurso hídrico está contaminado quando há presença de bactérias do grupo coliformes, independentemente de seu número por cada $100 \mathrm{~mL}$ de amostra d'água. Dessa forma, as águas do Córrego Paraíso estão contaminadas microbiologicamente.

As elevadas concentrações de coliformes termotolerantes, conforme visto na presença de todos os tubos positivos, e a queda nos teores de oxigênio dissolvido, são indicativas de grave contaminação por esgoto doméstico, que deteriora a qualidade de um curso hídrico (OLIVEIRA et al., 2017). No caso do Córrego Paraíso, a ausência de sistema de tratamento de efluente doméstico faz com que haja danos à sua qualidade, sobretudo no que diz respeito à presença de bactérias do grupo coliforme.

Todavia, outra questão relacionada ao aparecimento de coliformes em uma localidade está relacionada ao fato de não haver coleta de resíduos sólidos domiciliares, pois, quando descartado inadequadamente, o lixo pode contribuir para a proliferação desses micro-organismos e vetores de doenças (FERREIRA et al., 2017). O distrito de Vieira Machado, pelo fato de estar localizado em área rural, a coleta do lixo domiciliar não é realizada diariamente, principalmente nas regiões de maiores altitudes, o que pode ser um dos fatores que acarretam o aumento do índice de coliformes na água do Córrego Paraíso a partir da destinação incorreta desses resíduos.

A Escherichia coli é um dos micro-organismos mais comuns no corpo humano, habitando no trato digestório. Não é um patógeno comum, mas algumas dessas bactérias podem causar diarreia em decorrência da produção de enterotoxinas e provocar outras doenças à população humana, quando há ingestão de água contaminada (OLIVEIRA et al., 2015). Portanto, as águas do Córrego Paraíso, caso sejam ingeridas sem um tratamento devido, pode acarretar transtornos à saúde da população local. 
Com relação ao déficit de oxigênio dissolvido estimado, em $\mathrm{mg} / \mathrm{L}$, os valores para os pontos 1 , 2 e 3 foram, respectivamente: 0,$57 ; 0,73 ; 1,20$. Ou seja, em todos os pontos, houve perda de oxigênio. Essa perda foi aumentando do ponto 1 para o ponto 3, ou seja, em direção jusante do Córrego Paraíso. Fiorese (2019) afirma que resultados como estes podem indicar poluição da água principalmente por matéria orgânica, atrelada ao recebimento de efluentes domésticos, além da agropecuária praticada às margens dos rios, que pode causar danos à qualidade dos recursos hídricos por meio do transporte de sedimentos em direção aos mesmos através de precipitações pluviométricas. Dessa forma, as águas do Córrego Paraíso são vulneráveis à perda de oxigênio, em decorrência da ação antrópica nesse meio. Assim, pode interferir negativamente nas condições da biota aquática e prejudicar a qualidade da água para abastecimento humano.

Embora este trabalho seja baseado em uma análise preliminar, as águas do Córrego Paraíso sofrem com a presença de coliformes, mesmo com a turbidez e os índices de oxigênio dissolvido estando em conformidade com a legislação vigente. Dessa forma, há grande necessidade de melhorias de suas águas a partir de medidas de mitigação dos impactos ambientais que atingem este recurso hídrico, enfatizando ainda mais a relevância da implantação de ações para a melhoria da qualidade ambiental da localidade. Além disso, foi possível perceber que o distrito de Vieira Machado influencia na qualidade da água do Córrego Paraíso, o que é outro fator preocupante para as populações que desfrutam desse recurso hídrico.

\section{CONCLUSÃO}

Os parâmetros físico-químicos, com exceção do $\mathrm{pH}$, estavam em conformidade com a legislação. Todavia, a alta presença de coliformes em todos os pontos apontou contaminação fecal das águas do Córrego Paraíso. Os valores de turbidez e concentração e déficit de oxigênio dissolvido foram piorando na direção jusante, evidenciando, assim, que o distrito local influencia na qualidade da água. Portanto, a necessidade da implantação de ações de melhorias de saneamento ambiental é de extrema importância, para melhorar a qualidade ambiental deste recurso hídrico e oferecendo melhor qualidade de vida à fauna e, principalmente, às populações humanas desta região.

\section{REFERÊNCIAS}

ALVES, W. dos S.; SANTOS, L. N. S. dos.; MEDEIROS, V. S.; AQUINO, D. S. et al. Avaliação da qualidade da água e estado trófico do Ribeirão das Abóboras, em Rio Verde - GO, Brasil. Revista Geociências, São Paulo, v. 36, n. 1, p. 13-29, 2017. Disponível em: <https://www.revistageociencias.com.br/geociencias-arquivos/36/volu me36_1_files/36-1-artigo-02.pdf>.

ANDRADE, D.; FIORESE, C. H. U.; GOUVÊA, M. P. S.; RODRIGUES, R. C. Utilização de técnicas ambientais no monitoramento das águas do Rio Castelo- ES. In: Congresso Internacional das Águas, 3., 2017. Belo Horizonte. Anais... Belo Horizonte: RESAG, 2017.

BATISTA, D. F.; CABRAL, J. B. P.; ROCHA, T.; BARBOSA, G. R. Avaliação do oxigênio dissolvido nas águas do Ribeirão Paraíso em Jataí-GO e Córrego Tamanduá em Iporá-GO. Revista Caminhos de Geografia, Uberlândia, v. 18, n. 64, p. 296-309, dez. 2017. Disponível em: <http://www.seer.ufu.br/index.php/caminhosd egeografia/article/view/40935> 
BISOGNIN, R. P.; WEBER, F. H.; SILVA, B. R. da.; WOHLEMBERG, P. et al. Análise e divulgação da qualidade da água de nascentes, afluentes e pontos de captação do Arroio Lajeado Erval Novo no município de Três Passos - RS. Revista Gestão \& Sustentabilidade Ambiental, Florianópolis, v. 6, n. 2, p. 44-55, jul./set. 2017. Disponível em: <http://www.portaldeperiodicos.unisul.br/index.php/gestao_am biental/article/view/3625/0 >. doi: 10.19177/rgsa.v6e2201744-55

BRASIL. Conselho Nacional do Meio Ambiente. Resolução $n^{\circ}$ 357, de 17 de março de 2005. Dispõe sobre a classificação dos corpos d'água e diretrizes para o seu enquadramento, e dá outras providências. Diário Oficial da União, Brasília, DF, 2005.

BRASIL. Ministério da Saúde. Portaria n 2.914, de 12 de dezembro de 2011. Dispõe sobre os procedimentos de controle e de vigilância da qualidade da água para consumo humano e seu padrão de potabilidade. Diário Oficial da União, 2011.

BRASIL. Fundação Nacional de Saúde. Manual prático de análise de água. 4.ed. Brasília: Funasa, 2013. 150 p.

CETESB. Mortandade de peixes - pH. 2019. Disponível em: <https://cetesb.sp.gov. $\mathrm{br} / \mathrm{mortandade-peixes/alteracoes-fisicas-e-quimicas/ph/>.}$

FAGUNDES, A. K. B.; MENDES, T. A.; PEREIRA, T. S. R. Classificação preliminar de corpos d'água com base na resolução CONAMA n ${ }^{\circ} 357 / 2005$ : caso do rio Meia Ponte - GO. Revista Ciência e Natura, Santa Maria, v. 38, n. 3, p. 1382-1393, set./dez. 2016. Disponível em: <https://www.redalyc.org/html/4675/467547716025/>. doi: $10.5902 / 2179460 \times 21832$

FERREIRA, F. da S.; QUEIROZ, T. M. de.; SILVA, T. V. da.; ANDRADE, A. C. de O. À margem do rio e da sociedade: a qualidade da água em uma comunidade quilombola no estado de Mato Grosso. Revista Saúde e Sociedade, São Paulo, v. 26, n. 3, p. 822-828, 2017. Disponível em: <https://www.scielosp.org/article/ssm/cont ent/raw/?resource_ssm_path=/media/assets/sausoc/v26n3/0104-1290-sausoc-2603-00822.pdf>. doi: 10.1590/S0104-12902017166542

FIORESE, C. H. U. Estudo do oxigênio dissolvido aliado à análise do uso de solo da área de preservação permanente do Rio Castelo-ES, Brasil. Brazilian Journal of Development, Curitiba, v. 5, n. 1, p. 887-900, jan. 2019. Disponível em: <http://www.brjd.com.br/index.php/BRJD/article/view/1033>.

GARCIA, E. N. dos A.; MORENO, D. A. A. C.; FERNANDES, A. L. V. A importância da preservação e conservação das águas superficiais e subterrâneas: um panorama sobre a escassez da água no Brasil. Fórum Ambiental da Alta Paulista, v. 11, n. 6, p. 235-249, 2015. Disponível em: <http://www.amigosdanatureza.org.br/publicacoes/ index.php/forum_ambiental/article/view/1259>. doi: http://dx.doi.org/10.17271/198008 2711620151259 
GEOBASES. Imagens do mapeamento ES 2012-2015 disponíveis para download. Disponível em: <https://geobases.es.gov.br/novas-imagens-map-es2012-2015-sem-ecw>.

GLÓRIA, L. P.; HORN, B. C.; HILGEMANN, M. Avaliação da qualidade da água de bacias hidrográficas através da ferramenta do índice de qualidade da água - IQA. Revista Caderno Pedagógico, Lajeado, v. 14, n. 1, p. 103-119, 2017. Disponível em: $\quad$ <http://univates.br/revistas/index.php/cadped/article/view/1421>. doi: http://dx.doi.org/10.22410/issn.1983-0882.v14i1a2017.1421

INSTITUTO JONES DOS SANTOS NEVES. Shapefiles. 2019. Disponível em: $<$ http://ww w.ijsn.es.gov.br/mapas/>.

JORDÃO, E. P.; PESSÔA, C. A. Tratamento de esgotos domésticos. 7.ed. Rio de Janeiro: Associação Brasileira de Engenharia Sanitária e Ambiental, 2014. 1050 p.

LEITE, M. A.; DORNFELD, C. B.; MARÓSTICA, M.; DIAS, F. A.; PRADO, H. F. A. do. et al. Segurança hídrica em área rural. In: Simpósio Brasileiro de Recursos Hídricos, 21., 2015, Brasília. Anais... Brasília: Associação Brasileira de Recursos Hídricos, 2015.

MELLO, C. M.; RESENDE, J. C. de P. Análise microbiológica da água dos bebedouros da Pontifícia Universidade Católica de Minas Gerais campus Betim. Revista Sinapse Múltipla, v. 4, n. 1, p. 16-28, jul. 2015. Disponível em: <http://periodicos.pucminas.br/index.php/sinapsemultipla/article/view/9362>

NEVES, F. M. C.; CASTRO, F. B. G. de.; GODEFROID, R. S.; SANTOS, V. L. P. dos.; WAGNER, R. Avaliação da qualidade da água do Rio Bacacheri, Curitiba/PR. Revista Meio Ambiente e Sustentabilidade, v. 8, n. 4, p. 81-98, jan./jun. 2015. Disponível em: <file://C:/Users/Usuario/Downloads/425-1601-1-PB.pdf>.

OLIVEIRA, A. J. de.; SANTOS, M. C. H. G.; ITAYA, N. M.; CALIL, R. M. Coliformes termotolerantes: bioindicadores da qualidade da água destinada ao consumo humano. Atas de Saúde Ambiental, São Paulo, v. 3, n. 2, p. 24-29, ago. 2015. Disponível em: <http://www.revistaseletronicas.fmu.br/index.php/ASA/article/view/94 9/880>.

OLIVEIRA, S. C.; AMARAL, R. C.; ALMEIDA, K. C. de B.; PINTO, C. C. Qualidade das águas superficiais do Médio São Francisco após a implantação dos perímetros irrigados de Gorutuba/Lagoa Grande e Jaíba. Revista Engenharia Sanitária e Ambiental, v. 22, n. 4, p. 711-721, jul./ago. 2017. Disponível em: <http://www.scielo.br/pdf/esa/v22n4/1809-4457-esa-s1413-41522017136784.pdf>. doi: $10.1590 / S 1413-41522017136784$

PERCEBON, C. M.; BITTENCOURT, A. V. L.; ROSA FILHO, E. F. da. Diagnóstico da temperatura das águas dos principais rios de Blumenau, SC. Boletim Paranaense de Geociências, n. 56, p. 7-19, 2005. Disponível em: <https://revistas.ufpr.br/geociencias/article/viewFile/4904/3737>. 
RENOVATO, D. C. C.; SENA, C. P. S.; SILVA, M. M. F. Análise de parâmetros físico-químico das águas da barragem pública da cidade de pau dos ferros (RN) ph, cor, turbidez, acidez, alcalinidade, condutividade, cloreto e salinidade. In: IX Congresso de Iniciação Científica do IFRN - Tecnologia e Inovação para o Semiárido, 4., 2013, Natal. Anais... Natal: IFRN, 2013.

ROBERTO, M. da C.; GUIMARÃES, A. P. M.; RIBEIRO, J. L.; CARVALHO, A. V. de.; NERES, J. C. I. et al. Avaliação do $\mathrm{pH}$, turbidez, e análise microbiológica da água do Córrego Guará Velho em Guaraí, estado do Tocantins. Revista Desafios, v. 4, n. 4, p. 3-14, 2017. Disponível em: <https://sistemas.uft.edu.br/periodicos/index.php/desafi os/article/view/4108/11811>. doi: https://doi.org/10.20873/uft.2359-3652.2017v4n4p3

SANTOS, R. de S.; MOHR, T. Saúde e qualidade da água: análises microbiológicas e físico-químicas em análises subterrâneas. Revista Contexto \& Saúde, ljuí, v. 13, n. 25, p. 46-53, jul./dez. 2013. Disponível em: < https://www.revistas.unijui.edu.br/index.php/contextoesaude/article/view/2877>. doi: https://doi.org/10.21527/2176-7114.2013.24-25.46-53

SILVA, E. S. E.; OLIVEIRA, J. C. S. de. Avaliação da qualidade da água da Reserva Particular do Patrimônio Natural (RPPN) Seringal Triunfo, Rio Araguari, Ferreira Gomes-ap-Brasil. Revista Biota Amazônia, Macapá, v. 4, n. 2, p. 28-42, 2014. Disponível em: <https://periodicos.unifap.br/index.php/biota/article/view/786>. doi: http://dx.doi.org/10.18561/2179-5746/biotaamazonia.v4n2p28-42

STROHSCHOEN, A. A. G.; PÉRICO, E.; LIMA, D. F. B. de.; REMPEL, C. Estudo preliminar da qualidade da água dos rios Forqueta e Forquetinha, Rio Grande do Sul. Revista Brasileira de Biociências, Porto Alegre, v. 7, n. 4, p. 372-375, out./dez. 2009. Disponível em: <http://www.ufrgs.br/seerbio/ojs/index.php/rbb/article /viewFile/1227/892>.

ZSCHORNACK, T.; OLIVEIRA, T. M. N. de. Monitoramento e análise da qualidade da água da Bacia Hidrográfica do Rio Cachoeira no município de Joinville/SC (período 2011-2015). Acta Biológica Catarinense, Joinville, v. 4, n. 3, p. 29-40, out./dez. 2017. Disponível em: <http://periodicos.univille.br/index.php/ABC/articl e/view/453>. doi: http://dx.doi.org/10.21726/abc.v4i3.453 